\title{
Comparison of Physical Therapy Follow-Up of Patients with Operated and Non-Operated Lumbar Spinal Stenosis According to the Nottingham Health Profile-Pain Scale
}

\author{
Murat Baloğlu' ${ }^{*}$, Hüseyin Özevren² \\ ${ }^{1}$ Division of Physical Therapy and Rehabilitation, Diyarbakır Gazi Yaşargil Training and Research Hospital, Diyarbakır, Turkey \\ ${ }^{2}$ Department of Neurosurgery, Medical School, Dicle Unviersity, Diyarbakır, Turkey \\ Email: *murbal21@hotmail.com
}

How to cite this paper: Baloğlu, M. and Özevren, H. (2021) Comparison of Physical Therapy Follow-Up of Patients with Operated and Non-Operated Lumbar Spinal Stenosis According to the Nottingham Health Profile-Pain Scale. Open Journal of Modern Neurosurgery, 11, 234-241.

https://doi.org/10.4236/ojmn.2021.114027

Received: June 22, 2021

Accepted: October 9, 2021

Published: October 12, 2021

Copyright $\odot 2021$ by author(s) and Scientific Research Publishing Inc. This work is licensed under the Creative Commons Attribution International License (CC BY 4.0).

http://creativecommons.org/licenses/by/4.0/

\begin{abstract}
Background: Lumbar spinal stenosis (LSS) continues to be a major problem in societies, causing job loss and lowering quality of life. There are two types of treatment methods, physical therapy and surgery. If patients with LSS avoid treatment, they are likely to experience neurological deterioration in later years. Objective: The study aimed to evaluate the effect of physical therapy applied after decompression surgery or the effect of only applied physical therapy in patients with lumbar spinal stenosis. Materials and Methods: The results of the physical therapy follow-up of patients who had surgery and did not have surgery due to lumbar spinal stenosis between July 2014 and December 2019 were compared with each other. All patients received physical therapy for 6 months. Included were 42 patients who underwent decompression surgery due to LSS; 56 patients were not operated. Clinical outcomes were measured using the Nottingham Health Profile-Pain (NHP-Pain) scale at the initial, first, third and sixth months. The results were compared statistically. Results: The age of the operated patients was $54.69 \pm$ 8.42 (39 - 71), while the non-operated patients were $59.16 \pm 14.04(34-83)$. There was no significant difference in the statistical comparison $(\mathrm{p}=0.053)$. While the body mass index (BMI) of the operated patients was $29.43 \pm 4.99$ $(21-40)$, the BMI of the non-operated patients was $28.84 \pm 4.62(22-42)$. There was no significant difference in the statistical comparison $(\mathrm{p}=0.552)$. The scores of a 6-month physical therapy follow-up of patients were evaluated according to the NHP-pain scale. The values of patients who underwent surgery, initial - 1st month $(\mathrm{p}<0.001)$, 1st month - 3rd month $(\mathrm{p}=$ $0.028)$, 3rd month -6 th month $(\mathrm{p}=0.389)$ follow-up of the intervals were compared statistically. The values of non-operated patients, initial - 1st
\end{abstract}


month $(\mathrm{p}=0.008)$, 1st month -3rd month $(\mathrm{p}=0.013)$, 3rd month - 6th month $(\mathrm{p}=0.025)$ were compared statistically. Patients with and without surgery had significantly different initial pain scores $(\mathrm{p}<0.001)$. Conclusions: The NHP-Pain scores of the patients undergoing physical therapy with the operation were shown to provide more significant improvement than the group receiving only the physical therapy. Patients with LSS should be treated with an operation to obtain the maximum benefit of physical therapy.

\section{Keywords}

Lumbar Spinal Stenosis, Physical Therapy, Exercise, Operation

\section{Introduction}

Lumbar spinal stenosis (LSS) is described as narrowing of the spinal canal, root canals, or intervertebral foramen [1]. The clinical presentation of LSS occurs as a result of compression of the neural tissue or spinal nerve roots in the narrow canal [2]. LSS can cause various clinical syndromes, such as neurogenic claudication, back pain, radiculopathy, and cauda equina syndrome. People with LSS usually avoid walking due to pain and disturbance in the lower limbs, and the ability to walk properly decreases and causes loss of labor [3] [4].

While LSS can be other causes such as congenital [5], the most usual cause of LSS is the degenerative process that affects frequently as the age progresses, and the associated canal and root contraction and compression [6].

The clinical diagnosis of LSS requires both the presence of disease-specific complaints and symptoms and radiographic verification of narrowing or stenosis of the lumbar spinal canal. MRI and CT imaging examinations are the best diagnostic tools to show the diagnosis of LSS, bone structure, and pressure to the spinal cord and roots [7].

LSS patients receive two types of treatment. Patients are either physically treated after surgery or only physical therapy. The main purpose of the lumbar surgical treatment of LSS patients is to open the spinal canal, to relieve the spinal cord and roots [8]. The most frequently used surgical procedure in patients with LSS is laminectomy, and it is the decompressive procedure applied to relieve the spinal cord [9].

The Nottingham Health Profile-Pain (NHP-Pain) is a general quality of life questionnaire that measures the health problems perceived by the person and the level of these problems affecting their normal daily activities. The LSS with the patients was assessed using the NHP-Pain [10].

Body mass index (BMI) is a measure of estimated body fat, calculated by height and weight, valid for adult men and women [11]. LSS is currently the most common diagnosis for patients who increase with age [12].

The study aimed to evaluate the clinical effect of physical therapy with decompression surgery or only physical therapy for treating lumbar spinal stenosis. 


\section{Aim of the Work}

The objective of this study is to compare the physical therapy follow-up of patients with operated and non-operated lumbar spinal stenosis according to the Nottingham health profile-pain scale.

\section{Materials and Methods}

The results of the physical therapy follow-up of patients who had surgery and did not have surgery due to lumbar spinal stenosis between July 2017 and December 2020 were compared with each other. All patients received physical therapy for 6 months. Included were 42 patients who underwent decompression surgery due to LSS; 56 patients were not operated. Clinical outcomes were measured using the NHP-Pain scale at the initial, first, third and sixth months. The results were compared statistically. Ethics approval was provided by the Human Research Ethics Committees. Statistical analyzes were done with SPSS 20.0 (SPSS Inc., Chicago, IL, USA). Descriptive statistics are given as mean \pm standard deviation (min-max). We used independent sample t-test to compare the average outcomes of the BMI and age, at the surgical vs. nonsurgical treatment. The parametric repeated measures ANOVA with Student-Newman-Keuls post-hoc test and the non-parametric Friedman repeated measures test with Dunn's post-hoc test were used to reveal whether there was a significant difference within the follow-up monthly. Values of $\mathrm{p}<0.05$ were considered statistically significant.

\subsection{Diagnostic Imaging}

All patients underwent preoperative diagnostic imaging with magnetic resonance imaging or computed tomography. However, postoperative examinations of the patients in the surgery group were performed with computed tomography.

\subsection{Physical Therapy Procedure}

All patients received, based on their clinical and imaging diagnoses (CT and/or MRI), were diagnosed with LSS, and physical therapy was applied. Physical therapy was applied at home once a week for 6 months, the same treatment being in the hospital for the first month. Patients were treated with manual therapy, under the supervision of a physical therapist, flexion, and strengthening programs for back, and leg muscles and treadmill walking. Following the physical therapy sessions in the first month of the hospital, patients performed a home exercise program consisting of walking and flexion and strengthening exercises during a 5-month intervention [13].

\subsection{Surgical Procedure}

In LSS surgical operation, the spinal process of the facet joints and the unilateral and bilateral laminae of the relevant levels and the medial aspects of the facet joints are resected [14]. 


\section{Results}

The results of the physical therapy follow-up of patients who had surgery and did not have surgery due to lumbar spinal stenosis between July 2014 and December 2019 were compared with each other. The total number of patients receiving physical therapy due to lumbar spinal stenosis is 98 , of which 42 were operated and 56 were not operated. The age of the operated patients was $54.69 \pm$ 8.42 (39 - 71), while the non-operated patients were $59.16 \pm 14.04(34-83)$. There was no significant difference in the statistical comparison $(\mathrm{p}=0.053)$ (Figure 1(a)). While the BMI of the operated patients was $29.43 \pm 4.99$ (21 - 40), the BMI of the non-operated patients was $28.84 \pm 4.62(22-42)$. There was no significant difference in the statistical comparison $(\mathrm{p}=0.552)$ (Figure $1(\mathrm{~b})$ ).

The scores of a 6-month physical therapy follow-up of operated patients with and without lumbar spinal stenosis were evaluated according to the NHP-pain scale. The values of patients underwent surgery, preoperative-initial $50.71 \pm 8.49$ (36 - 64), 1st month $29.38 \pm 5.64$ (18 - 42), 3rd month $25.79 \pm 4.05$ (16 - 35), 6th month $23.76 \pm 4.06(18-35)$ were calculated. Statistically, initial-1st month $(\mathrm{p}<$
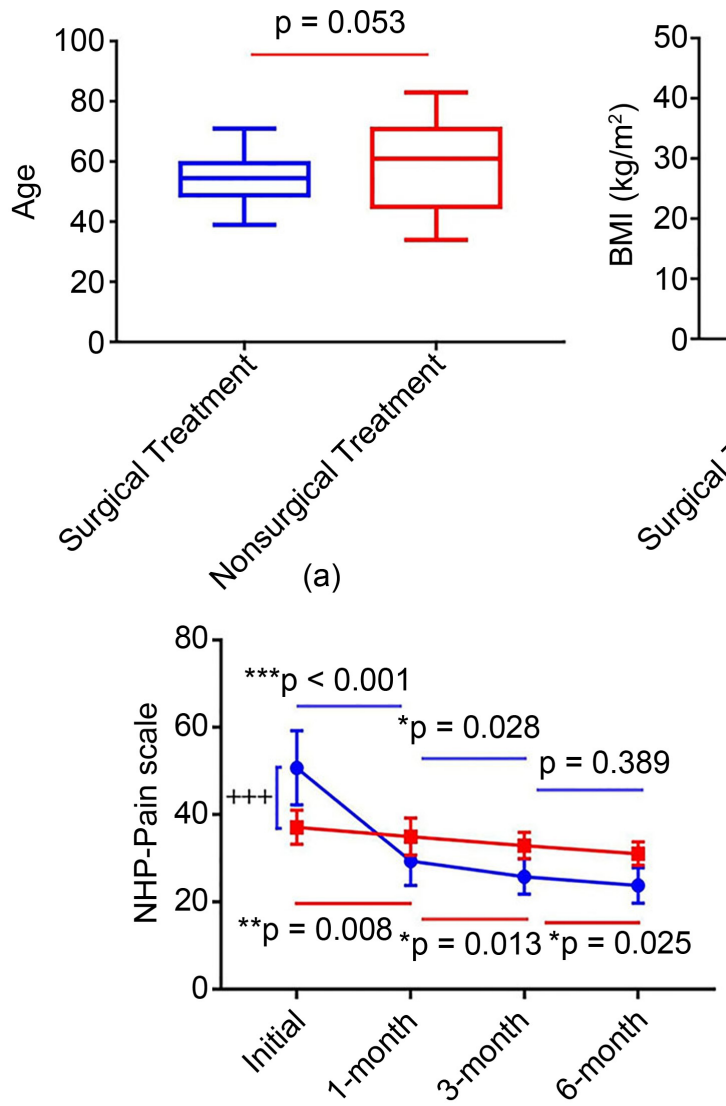

(c)

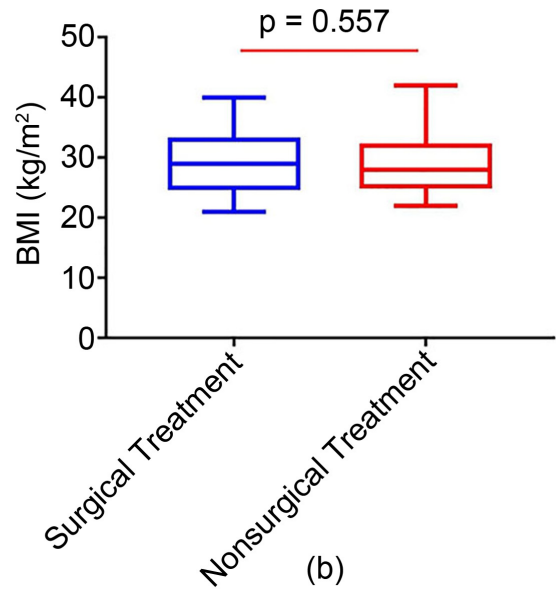

-Surgical Treatment

- Nonsurgical Treatment

Figure 1. (a) Comparison of surgical and non-surgical patients in terms of age; (b) Statistical evaluation of surgical and non-surgical patients according to BMI scores; (c) Comparison of the NHP-pain scale outcomes between the follow-up of the nonsurgical and surgical treatment. (BMI): Body mass index; (NHP): Nottingham Health Profile. ${ }^{*} \mathrm{p}<$ 0.05 were considered statistically significant. ${ }^{* *} \mathrm{p}<0.01,{ }^{* * *} \mathrm{p}<0.001$. 
$0.001)$, 1st month-3rd month $(\mathrm{p}=0.028)$, 3rd month-6th month $(\mathrm{p}=0.389)$ follow-up of the intervals were compared (Figure 1(c), blue color).

The values of non-operated patients, initial $37.11 \pm 3.89$ (32 - 51), 1st month $34.96 \pm 4.24$ (28 - 42), 3rd month $32.93 \pm 3.05$ (26 - 39), 6th month $31.04 \pm 2.7$ (26 - 36) was calculated. Statistically, initial-1st month $(\mathrm{p}=0.008)$, 1st month3rd month ( $\mathrm{p}=0.013)$, 3rd month-6th month ( $\mathrm{p}=0.025)$ follow-up of the intervals were compared. Patients with and without surgery had significantly different initial pain scores $(\mathrm{p}<0.001)$ (Figure $1(\mathrm{c})$, red color).

\section{Discussion}

LSS has a respectable effect on mobility, functionality, and characteristics of life. LSS is one of the most common spinal disorders treated in older adults and its prevalence will keep going to increase due to an aging population and a trend toward aging. LSS is a clinical condition of a hip or lower limb ache, with or without back pain, related to a decrease in the available space for a neural and vascular constituent in the lumbar spine [15]. Current advances in imaging technology, development in diagnostic accuracy, and aging of the population have led to a remarkable increase in the diagnosis of LSS [16]. LSS is one of the most common causes of spine surgery in older individuals and has become one of the most common circumstances in orthopedic and neurosurgery practices [17]. Lumbar stenosis is brought along by changes in the aging of the spine, incorporating facet joint hypertrophy, loss of intervertebral disc height, disc distension, osteophyte structure, and hypertrophy of the ligamentum flavum, and excessive riding on the spine with increased obesity [18]. BMI calculated by height and weight, valid for adult men and women [11]. In our study, there was no statistically significant difference in the BMI of the operated and non-operated patients, and when compared with each other.

In the pathology of lumbar spinal stenosis, the degenerative occurrence in the lumbar spine causes stenosis, known as compression of the neural tissue in the spine and/or a root canal, resulting in severe pain and loss of function [15]. As the age progresses in patients with LSS, complaints increase and symptoms begin to progress [6]. Patients with increased LSS complaints either continue with only physical therapy considering the risks of surgery or continue with physical therapy after surgery [19]. In our study, no statistically significant difference was found in the statistical study when we compared the operated and non-operated patients in terms of their ages.

Surgical treatment was considered to be the ideal treatment after conservative treatment is inadequate [20]. Surgical treatment of LSS aims to adequately relieve nerve roots and dural sac without damaging spinal stability [9]. The most common indication for lumbar surgery in patients with LSS is pain and neurogenic claudication due to spinal cord and root compression. The main purpose of surgical treatment is to relieve the spinal canal and roots [21]. There are many surgical techniques for LSS treatment, such as total laminectomy, hemilami- 
nectomy, and laminotomy, etc. Currently, there is no common technique for LSS treatment [22]. Laminectomy, the surgical procedure for LSS treatment, is essential to remove laminae, spinous processes, ligamentum flavum, and part of the articular process as much as necessary during decompression [23]. Which method is the most beneficial and least harmful for the patient is decided upon imaging tests and examination results.

Conservative treatment can increase mobility or motion control in the lumbar spine by acting directly on pain with medications and physical therapy [24], both active (exercise) and passively. Physical therapy can improve overall health and potentially lead to decreased pain and improved function [25].

In the study of 100 LSS patients performed by Amundsen T et al. [26] concluded that although initially suggested a conservative approach, the most appropriate approach was surgical treatment.

In the study of Weinstein JN, et al. [9] in 289 LSS patients, a significant improvement was observed in patients undergoing surgery versus not undergoing surgery. In the study of Malmivaara et al. [19] a 2-year follow-up of 94 LSS patients reported more significant improvement in leg and back pain and general disability in patients with decompressive surgery.

\section{Conclusion}

We obtained NHP-pain scale evaluation performed with 98 patients for the NHP-pain, comparing physical therapy with decompression surgery versus only physical therapy. Pain scores of patients who received physical therapy after surgery were found to be lower than those who received physical therapy alone. In our 6-month follow-up, it was seen that the post-surgical physical therapy was more beneficial. Finally, research on LSS treatment should be improved by increasing the number of patients and extending clinical follow-up.

\section{Limitations}

The NHP-Pain scale in this study was the first study on patients with LSS and relatively small. The results might be better established with a larger sample size. In the future, larger populations of LSS patients should be studied.

\section{Conflicts of Interest}

The authors declare no conflicts of interest regarding the publication of this paper.

\section{References}

[1] Deer, T., Sayed, D., Michels, J., Josephson, Y., Li, S. and Calodney, A.K. (2019) A Review of Lumbar Spinal Stenosis with Intermittent Neurogenic Claudication: Disease and Diagnosis. Pain Medicine, 20, S32-S44. https://doi.org/10.1093/pm/pnz161

[2] Airaksinen, O., Herno, A., Turunen, V., Saari, T. and Suomlainen, O. (1997) Surgical Outcome of 438 Patients Treated Surgically for Lumbar Spinal Stenosis. Spine, 
22, 2278-2282. https://doi.org/10.1097/00007632-199710010-00016

[3] Iversen, M.D. and Katz, J.N. (2001) Examination Findings and Self-Reported Walking Capacity in Patients with Lumbar Spinal Stenosis. Physical Therapy, 81, 1296-12306. https://doi.org/10.1093/ptj/81.7.1296

[4] Tomkins-Lane, C.C., Holz, S.C., Yamakawa, K.S., Phalke, V.V., Quint, D.J., Miner, J., et al. (2012) Predictors of Walking Performance and Walking Capacity in People with Lumbar Spinal Stenosis, Low Back Pain, and Asymptomatic Controls. Archives of Physical Medicine and Rehabilitation, 93, 647-653. https://doi.org/10.1016/j.apmr.2011.09.023

[5] Binder, D.K., Schmidt, M.H. and Weinstein, P.R. (2002) Lumbar Spinal Stenosis. Seminars in Neurology, 22, 157-166. https://doi.org/10.1055/s-2002-36539

[6] Minamide, A., Yoshida, M., Iwahashi, H., Simpson, A.K., Yamada, H., Hashizume, H., et al. (2017) Minimally Invasive Decompression Surgery for Lumbar Spinal Stenosis with Degenerative Scoliosis: Predictive Factors of Radiographic and Clinical Outcomes. Journal of Orthopaedic Science, 22, 377-383.

https://doi.org/10.1016/j.jos.2016.12.022

[7] Perez, F.A., Quinet, S., Jarvik, J.G., Nguyen, Q.T., Aghayev, E., Jitjai, D., et al. (2019) Lumbar Spinal Stenosis Severity by CT or MRI Does Not Predict Response to Epidural Corticosteroid versus Lidocaine Injections. American Journal of Neuroradiology, 40, 908-915. https://doi.org/10.3174/ajnr.A6050

[8] Macedo, L.G., Hum, A., Kuleba, L., Mo, J., Truong, L., Yeung, M., et al. (2013) Physical Therapy Interventions for Degenerative Lumbar Spinal Stenosis: A Systematic Review. Physical Therapy, 93, 1646-1660.

https://doi.org/10.2522/ptj.20120379

[9] Weinstein, J.N., Tosteson, T.D., Lurie, J.D., Tosteson, A.N.A., Blood, E., Hanscom, B., et al. (2008) Surgical versus Nonsurgical Therapy for Lumbar Spinal Stenosis. New England Journal of Medicine, 358, 794-810. https://doi.org/10.1056/NEJMoa0707136

[10] Saraph, V., Lerch, C., Walochnik, N., Bach, C.M., Krismer, M. and Wimmer, C. (2004) Comparison of Conventional versus Minimally Invasive Extraperitoneal Approach for Anterior Lumbar Interbody Fusion. European Spine Journal, 13, 425-431. https://doi.org/10.1007/s00586-004-0722-4

[11] Rihn, J.A., Radcliff, K., Hilibrand, A.S., Anderson, D.T., Zhao, W., Lurie, J., et al. (2012) Does Obesity Affect Outcomes of Treatment for Lumbar Stenosis and Degenerative Spondylolisthesis? Analysis of the Spine Patient Outcomes Research Trial (SPORT). Spine, 37, 1933-1946. https://doi.org/10.1097/BRS.0b013e31825e21b2

[12] Rajasekaran, S., Thomas, A., Kanna, R.M. and Prasad Shetty, A. (2013) Lumbar Spinous Process Splitting Decompression Provides Equivalent Outcomes to Conventional Midline Decompression in Degenerative Lumbar Canal Stenosis: A Prospective, Randomized Controlled Study of 51 Patients. Spine, 38, 1737-1743. https://doi.org/10.1097/BRS.0b013e3182a056c1

[13] Minetama, M., Miyake, T., Moriki, T., et al. (2016) Multimodal Assessments of Effectiveness of Physical Therapy for Patients with Lumbar Spinal Stenosis. Jacobs Journal of Physiotherapy and Exercise, 2, Article No. 16.

[14] Thome, C., Zevgaridis, D., Leheta, O., Bäzner, H., Pöckler-Schöniger, C., Wöhrle, J., et al. (2005) Outcome after Less-Invasive Decompression of Lumbar Spinal Stenosis: A Randomized Comparison of Unilateral Laminotomy, Bilateral Laminotomy, and Laminectomy. Journal of Neurosurgery: Spine, 3, 129-141.

https://doi.org/10.3171/spi.2005.3.2.0129 
[15] Watters, W.C., Baisden, J., Gilbert, T.J., Kreiner, S., Resnick, D.K., Bono, C.M., et al. (2008) Degenerative Lumbar Spinal Stenosis: An Evidence-Based Clinical Guideline for the Diagnosis and Treatment of Degenerative Lumbar Spinal Stenosis. The Spine Journal, 8, 305-310. https://doi.org/10.1016/j.spinee.2007.10.033

[16] Haig, A.J., Tong, H.C., Yamakawa, K.S., Quint, D.J., Hoff, J.T., Chiodo, A., et al. (2006) Spinal Stenosis, Back Pain, or No Symptoms at All? A Masked Study Comparing Radiologic and Electrodiagnostic Diagnoses to the Clinical Impression. Archives of Physical Medicine and Rehabilitation, 87, 897-903.

https://doi.org/10.1016/j.apmr.2006.03.016

[17] Deyo, R.A. and Mirza, S.K. (2006) Trends and Variations in the Use of Spine Surgery. Clinical Orthopaedics and Related Research, 443, 139-146. https://doi.org/10.1097/01.blo.0000198726.62514.75

[18] Knutsson, B., Sandén, B., Sjödén, G., Järvholm, B. and Michaëlsson, K. (2015) Body Mass Index and Risk for Clinical Lumbar Spinal Stenosis: A Cohort Study. Spine, 40, 1451-1456. https://doi.org/10.1097/BRS.0000000000001038

[19] Malmivaara, A., Slätis, P., Heliövaara, M., Sainio, P., Kinnunen, H., Kankare, J., et al. (2007) Surgical or Nonoperative Treatment for Lumbar Spinal Stenosis? A Randomized Controlled Trial. Spine, 32, 1-8. https://doi.org/10.1097/01.brs.0000251014.81875.6d

[20] Pearson, A.M., Lurie, J.D., Blood, E.A., Frymoyer, J.W., Braeutigam, H., An, H., Girardi, F.P. and Weinstein, J.N. (2008) Spine Patient Outcomes Research Trial: Radiographic Predictors of Clinical Outcomes After Operative or Nonoperative Treatment of Degenerative Spondylolisthesis. Spine, 33, 2759-2766. https://doi.org/10.1097/BRS.0b013e31818e2d8b

[21] Choi, W.S., Oh, C.H., Ji, G.Y., Shin, S.C., Lee, J.-B., Park, D.-H., et al. (2014) Spinal Canal Morphology and Clinical Outcomes of Microsurgical Bilateral Decompression via a Unilateral Approach for Lumbar Spinal Canal Stenosis. European Spine Journal, 23, 991-998. https://doi.org/10.1007/s00586-013-3116-7

[22] Kalff, R., Ewald, C., Waschke, A., Gobisch, L. and Hopf, C. (2013) Degenerative Lumbar Spinal Stenosis in Older People: Current Treatment Options. Deutsches Arzteblatt international, 110, 613-624. https://doi.org/10.3238/arztebl.2013.0613

[23] Phan, K., Teng, I., Schultz, K. and Mobbs, R.J. (2017) Treatment of Lumbar Spinal Stenosis by Microscopic Unilateral Laminectomy for Bilateral Decompression: A Technical Note. Orthopaedic Surgery, 9, 241-246. https://doi.org/10.1111/os.12335

[24] Negrini, S., Giovannoni, S., Minozzi, S., Barneschi, G., Bonaiuti, D., Bussotti, A., et al. (2006) Diagnostic Therapeutic Flow-Charts for Low Back Pain Patients: The Italian Clinical Guidelines. Europa Medicophysica, 42, 151-170.

[25] Tomkins-Lane, C.C., Lafave, L.M., Parnell, J.A., Rempel, J., Moriartey, S., Andreas, Y., et al. (2015) The Spinal Stenosis Pedometer and Nutrition Lifestyle Intervention (SSPANLI): Development and Pilot. The Spine Journal, 15, 577-586. https://doi.org/10.1016/j.spinee.2014.10.015

[26] Amundsen, T., Weber, H., Nordal, H.J., Magnaes, B., Abdelnoor, M. and Lilleâs, F. (2000) Lumbar Spinal Stenosis: Conservative or Surgical Management? A Prospective 10-Year Study. Spine, 25, 1424-1435. https://doi.org/10.1097/00007632-200006010-00016 